\title{
A Educação Física escolar e seus dilemas contemporâneos: há pouca experiência nas experiências?
}

School Physical Education and its contemporary dilemmas: is there little experience in the experiences?

La Educación Física escolar y sus dilemas contemporáneos: hay poca experiencia en las experiencias?

\author{
George Ivan da Silva Holanda ${ }^{\mathrm{I}}$, Gabriel Carvalho Bungenstab ${ }^{\mathrm{II}}$
}

\begin{abstract}
Resumo
Este estudo procura analisar possíveis contribuições que a discussão filosófica sobre experiência traz para se pensar o ensino das práticas corporais na escola. Para isso, o texto recorre às análises sobre a (re)configuração da categoria experiência na modernidade e defende, no âmbito da Educação Física, que se pense a experiência a partir de um viés enriquecedor: menos centralizado em um ensino fechado/instrumental e mais preocupado com um ensino das práticas corporais de maneira aberta/inesperada. Nesse sentido, o estudo sugere que a tríade práticas corporais/experiência/Educação Física pode enriquecer as experiências corporais, dando um novo sentido à aprendizagem.
\end{abstract}

Palavras-chave: Experiência; Ensino Fundamental e Médio; Práticas Corporais; Educação Física

\begin{abstract}
This study seeks to analyze possible contributions that the philosophical discussion about experience brings to think about the teaching of the body practices at school. For this, the text uses the analysis on the (re)configuration of the experience category in modernity and defends, within the scope of Physical Education, that one thinks of experience from an enriching point: less centralized in a closed / instrumental teaching and more concerned with an open / unexpected teaching of bodily practices. In this sense, the study suggests that the triad body practices /experience / Physical Education can enrich bodily experiences, giving a new meaning to learning.
\end{abstract}

Keywords: Experience; Elementary and High School Education; Body Practices; Body Practices; Physical Education

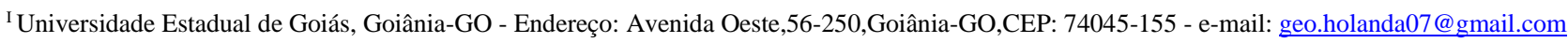

${ }^{\text {II } U n i v e r s i d a d e ~ E s t a d u a l ~ d e ~ G o i a ́ s, ~ G o i a ̂ n i a-G O ~-~ e-m a i l: ~ g a b r i e l c a r v @ m s n . c o m ~}$
} 


\section{Resumen}

Este estudio busca analizar posibles contribuciones que la discusión filosófica sobre experiencia trae para pensar la enseñanza de las prácticas corporales en la escuela. Para ello, el texto recorre los análisis sobre la (re)configuración de la categoría experiencia en la modernidad y defiende, en el ámbito de la Educación Física, que se piense la experiencia a partir de un sesgo enriquecedor: menos centralizado en una enseñanza cerrada / instrumental y más preocupado con la enseñanza de las prácticas corporales de manera abierta / inesperada. En este sentido, el texto sugiere que la tríada práctica corporal / experiencia / Educación Física puede enriquecer las experiencias corporales, dando un nuevo sentido al aprendizaje.

Palabras clave: Experiencia; Educación Primaria y Secundaria; Prácticas corporales; Educación Física

\section{Introdução}

A constituição dos saberes escolares se dá por meio de sistematizações, seleções, hierarquizações e organizações do conhecimento. Nesse contexto, a Educação Física (EF) se apresenta na escola como mais uma disciplina capaz de transmitir conhecimento e o faz por meio de diversas propostas metodológicas de ensino, como as propositivas sistematizadas (abordagens crítico-superadora; críticoemancipatória; aptidão física/saúde e concepção de "aulas abertas") e as propositivas não sistematizadas (abordagens construtivista, do lazer, desenvolvimentista, dentre outras) apresentadas por Castellani Filho (1999).

Segundo González e Fensterseifer (2010), a EF possibilita, por meio do se-movimentar ${ }^{1}$, um maior conhecimento do próprio corpo, da sua capacidade de, pelo movimento, estabelecer relação com o meio que o cerca. Nesse sentido, os autores ainda apontam que a EF ficaria incumbida de oportunizar o acesso a outras possibilidades de movimentos, distintas daquelas que os estudantes já possuem contato ao longo de sua existência, por meio da cultura na qual estão inseridos. Ou seja, uma das atribuições da EF também é proporcionar experiências pedagógicas diante dos mais diferentes tipos de práticas corporais. Dessa maneira, o objetivo deste ensaio é fomentar a discussão a respeito da pobreza/riqueza da experiência na EF escolar, partindo da ideia de que, como já ressaltado por Almeida e Fensterseifer (2011, p. 254), “[...] há pouca experiência nas experiências".

No que tange à elaboração, trata-se de uma pesquisa de cunho qualitativo. Segundo Triviños (1987, p. 137), “a pesquisa qualitativa não admite visões isoladas, parceladas, estanques. Ela se desenvolve em interação dinâmica retroalimentando-se, reformulando-se constantemente". Por isso, neste tipo de pesquisa há maior liberdade para o pesquisador desenvolver seu estudo. De tal modo, este ensaio

\footnotetext{
${ }^{1}$ Para Kunz (2005), o se-movimentar humano, a partir do referencial fenomenológico, se dá na relação que o sujeito estabelece com o mundo e os significados advindos desta relação que tem a linguagem e o movimento como elementos fundantes.
} 
se fundamenta na revisão bibliográfica que, para Gil (2008, p. 44), “[...] é desenvolvida com base em material já elaborado, constituído principalmente de livros e artigos científicos”. Weller e Pfaff (2011) sugerem que estudos de cunho qualitativo, além de serem importantes para elaboração de pesquisas e teorias, também colaboram para o processo formativo de profissionais do campo da educação (e da EF). Dessa forma, podem enriquecer a prática pedagógica dos professores.

Este ensaio se organiza a partir do seguinte itinerário reflexivo: 1) apresentar o conceito de práticas corporais e discutir suas possibilidades diante da categoria experiência; 2) debater sobre o conceito de experiência e suas (re)configurações na modernidade e 3) discutir as relações entre experiência e EF escolar a partir do ensino das práticas corporais.

\section{0 termo práticas corporais}

Para Lazzarotti Filho et al. (2009), o termo "práticas corporais" aparece pela primeira vez na literatura da área no ano de 1995. O autor salienta que a grande concentração de obras com o uso do termo começou a surgir a partir do ano 2000, recebendo uma impulsão a partir daí, podendo ser encontrado em artigos científicos, dissertações e também em teses.

Apesar da grande divulgação do termo, os autores explicam que há uma indefinição do que venha a ser o conceito de práticas corporais, tendo em vista que seu uso está presente tanto nas produções das Ciências da Saúde, quanto em áreas como a História, a Antropologia e a Sociologia. No entanto, foi encontrada a maior concentração de obras com uso da nomenclatura em produções inerentes à EF, o que mostra maiores aproximações com esse campo do conhecimento.

O conceito utilizado neste trabalho aproxima-se da compreensão que Silva et al. (2009) fazem, qual seja: as práticas corporais são fenômenos sociais concretos, que possuem como conteúdos os esportes, os jogos, as artes circenses, as danças, as lutas, entre outras. Os autores também sugerem que junto a esses conteúdos sejam acrescidas as práticas corporais de aventura, devido a atual importância desse tipo de prática para o ensino escolar, principalmente pelo seu caráter de novidade, o que pode contribuir para proporcionar novas experiências corporais na escola.

Para Silva et al. (2009), a principal contribuição para o entendimento das práticas corporais está na sua relação com a cultura, isto é, o modo de compreensão proporcionado pelo conceito permite uma aproximação das manifestações culturais com as diversas dimensões do movimento humano, fazendo assim da dimensão corporal seu maior componente. 
Outro ponto importante que se encontra no conceito de práticas corporais é sua aproximação com aspectos lúdicos, isso permite que o sujeito que toma contato com algum dos conteúdos inerentes às práticas tenha possibilidade de experimentar aquela ação de modo significativo e singular, uma vez que a ludicidade 2 é algo ímpar ao ser humano, apesar da sua pouca visibilidade nas escolas modernas.

Para Lazzarotti Filho et al. (2009), é importante considerar os aspectos subjetivos do termo "práticas corporais", uma vez que se trata menos de um termo fechado e mais de um elemento da cultura que possibilita a abertura a novas experiências corporais. Silva et al. (2009, p. 24) salientam que, com "as práticas corporais desenvolvidas nessa perspectiva da experiência, pode-se ter alguma esperança em contribuir com o desenvolvimento de capacidades humanas". Nesse sentido, percebe-se que as práticas corporais possibilitam um intercâmbio entre a experiência e o movimento. É esta a justificativa para o alinhamento entre esses dois conceitos.

Faz-se necessário conceituar e, em seguida, explicar o que este trabalho compreende como experiência, uma vez que esse termo não possui apenas um significado, sendo, inclusive, muito utilizado no saber do senso comum. Inevitavelmente, chega-se à questão: o que é experiência?

\section{0 debate sobre a experiência: entre a pobreza e a riqueza}

O conceito de experiência sofreu (e tem sofrido) variações ao longo do tempo. Seu uso foi destacado na Filosofia, com importantes autores, como Platão e Aristóteles, passando por John Dewey, até chegar ao seu desenvolvimento numa perspectiva mais moderna, com escritos também consagrados de Walter Benjamin e Jorge Larrosa Bondía.

O ensaísta e filósofo alemão, Walter Benjamin, ao apresentar sua teoria da experiência, não o faz de modo sistêmico; ao contrário, o conceito de experiência aparece de formas variadas ao longo de sua produção textual. A primeira vez que Benjamin discute esse conceito em seus ensaios foi no ano de 1913, período em que o autor era apenas um jovem alemão inconformado com algumas questões inerentes à juventude. Assim, nesse primeiro momento, segundo Silva (2012, p. 19), Benjamin dá ao conceito de experiência (Erfahrung) um caráter de investidura "contra o poder da autoridade da experiência do mais velho". Para o autor, os adultos (Erwachsene) encaram-se como possuidores de um conhecimento

\footnotetext{
2 Para Luckesi (1998, p. 3), a ludicidade "é um fenômeno interno do sujeito, que possui manifestações no exterior". Em outras palavras, é aquilo que é sentido, experimentado pelo sujeito. Ainda segundo o autor, o ato lúdico proporciona uma experiência em sua plenitude para quem a vive.
} 
adquirido pela vida, o qual, por ser limitante, também os limita, transformando-os, na realidade, em desencorajadores das experiências que podem vir a ter seus jovens filhos.

Benjamin (1984, p. 23), ao referir-se a essas características inerentes aos adultos, sublinha: "conhecemos outros pedagogos (pais) cuja amargura não nos proporciona nem sequer os curtos anos de ‘juventude': sisudos e cruéis querem nos empurrar desde já para a escravidão da vida". Segundo o autor, tal fato faz com que se encare a juventude como uma efemeridade, uma passarela para uma determinada “experiência”, refletida como uma vida monótona, enfadonha e pobre de ideias dos adultos.

Ainda no tocante ao conceito de experiência, Benjamin (1986) refere-se a ele como um conhecimento que é acumulado no transcorrer das gerações e que é passado de pessoa para pessoa, geralmente, por meio de fábulas, provérbios, parábolas, histórias. Ela possui um caráter de herança, de algo que se passa a posteridade, principalmente aos jovens. Pode-se dizer que é uma espécie de saber, ensinamento que pode ser transmitido, ou como o autor costuma colocar, intercambiado.

Para o autor, o intercâmbio de experiências sempre foi um modo seguro de transmissão de aprendizagens para a geração posterior, mas essa capacidade ficou seriamente comprometida após a primeira guerra mundial. Para sustentar essa hipótese, Benjamin (1986, p. 115) aponta que em sua época “[...] já se podia notar que os combatentes tinham voltado silenciosos do campo de batalha. Mais pobres em experiências comunicáveis e não mais ricos". É isso que o filósofo sugere como motivo para a quase extinção da capacidade de narrar experiências das pessoas; o intenso sofrimento das guerras de trincheiras, a experiência econômica trazida pela inflação, a experiência de submeter o corpo à extrema fome, a experiência moral de seus governantes, problemas pelos quais passou a Europa.

Agamben (2005), discorrendo sobre o tema, salienta que o sujeito, fruto deste processo, já não possui condições de conhecer-se a si mesmo. Em outros termos, o homem moderno viu-se também expropriado de sua própria experiência. Desse modo, “[...] a incapacidade de fazer e transmitir experiência talvez seja um dos poucos dados certos de que disponha sobre si mesmo" (GAGNEBIN, 2006, p. 21). No entanto, a destruição da experiência foi condição necessária para a existência de uma sociedade moderna, nos moldes em que hoje ela está posta.

Benjamin (1986, p. 105) salienta que esse acontecimento foi fundamental para que houvesse uma ruptura da experiência na modernidade, dando seu lugar ao conceito de vivência (Erlebnis). Para esse teórico, a vivência forma-se por "dados isolados" que são "rigorosamente fixados na memória". Enquanto que a experiência tinha relação com a tradição e a memória, podendo acontecer na forma individual e coletiva; a vivência, por outro lado, limita-se à esfera do individual, ao efêmero e passageiro, características tipicamente modernas. 
Nas palavras de Calou e Marciel (2017), a distinção entre Erfahrung e Erlebnis é vital para a teorização benjaminiana acerca da modernidade. Para esses autores, quando ocorre o esgotamento de todas as características trazidas por Benjamin sobre experiência (ser individual e coletiva, proceder de tradição, ser transmissível), bem como da aniquilação das possibilidades de sua narração, surge a vivência, que é balizada em um quadro isolamento social, no qual os acontecimentos se dão, em sua grande maioria, no campo individual.

Apesar de deixar um quadro de aparente impossibilidade de experiência na modernidade, autores mais contemporâneos tem se debruçado sobre o tema e trazido significativas contribuições. Um dos que tem se destacado é Jorge Larrosa Bondía, que apresenta nos seus escritos uma nova forma para pensarmos a categoria experiência. Para esse autor o conceito de experiência é definido como "[...] o que nos passa, o que nos acontece, o que nos toca" (BONDÍA, 2002, p. 21). O filósofo espanhol ainda complementa afirmando que a experiência não pode ser confundida com aquilo que se passa, que acontece ou que toca, mas sim, com aquilo que alcança a subjetividade de cada sujeito, mudando algo em seu ser, transformando-o, deixando algo significativo para seu eu.

Segundo Bondía (2002), há alguns fatores que favorecem o empobrecimento da experiência - seja na educação ou fora dela - são eles: 1) o excesso de informação despejada sobre as cabeças dos sujeitos, transformando-os em seres consumidores de informações, afastando-os do conhecimento e da troca de experiências pela narração; 2) o excesso de opinião. Segundo o autor há, na modernidade, a necessidade de formar opiniões sobre tudo e isso afasta o sujeito da experiência. Nesse sentido, experiência passa a significar um mero experimento ${ }^{3}$, um acontecimento efêmero, uma vivência.

Ainda desenvolvendo a ideia acima, o autor coloca outros dois fatores da pobreza de experiências hodierna: a falta de tempo e o excesso de trabalho. Nessa sociedade, que é sempre acelerada, quase nunca sobra tempo para se sensibilizar com algo, há sempre uma busca por prazeres instantâneos e fugazes. Por outro lado, o trabalho também toma o restante do tempo, principalmente porque é por meio dele que se realiza a busca incessante por dinheiro. Esse fato afasta os sujeitos de outros tipos de atividades, como, por exemplo, envolverem-se com práticas corporais.

Percebe-se que todos esses fatores influenciam no empobrecimento de experiência não só dos alunos e dos professores, mas de toda a humanidade. Nota-se que esse problema está muito além dos muros da escola, mas talvez encontre nesse ambiente de ensino formal um lugar de resistência e fuga.

\footnotetext{
${ }^{3}$ Neste ensaio vivência e experimento possuem o mesmo valor semântico.
} 
Bondía (2002), na tentativa de superação da visão da educação pelos pares ciência/técnica ou teoria/prática, sugere uma educação mais existencial e mais estética, pensada a partir do par experiência/sentido. Isto será feito, segundo ele, explorando o significado de algumas palavras, já que elas produzem sentidos e podem criar realidades, além de possuírem elementos de subjetivação. O autor salienta que é importante estar atento ao uso do conceito experiência, pois, sobretudo na educação, há um abuso no uso desse conceito, já que ele, muitas vezes, é tratado de forma banal. Esse tipo de problema tem causado confusão entre experiência e experimento. $\mathrm{O}$ experimento está ligado a algo eminentemente prático, ao saber fazer que nega as outras dimensões da experiência.

Temendo que essa confusão pudesse gerar contradições acerca do entendimento desse conceito na Educação, Bondía (2011) elenca cinco princípios da experiência que marca sua posição oposta ao experimento, são eles: o caráter de singularidade, pois a experiência apesar de se dar também em grupo é singular e única para cada um; o caráter da irrepetibilidade, pois a mesma experiência não se repete, apesar de que podemos refletir sobre ela ou intercambiá-la; o caráter da pluralidade, já que a experiência é sempre plural, rica em significados; o caráter da incerteza, referente à aventura, ao risco e ao perigo que há nas possibilidades de experiência, pois não se pode prever uma experiência e, por último, o caráter da liberdade, já que a experiência precisa da liberdade para acontecer.

Feita a demarcação do conceito, o filósofo espanhol deixa algumas indicações sobre como o sujeito moderno pode agir para que seja capaz de ter experiências. Para esses sujeitos traduzirem os acontecimentos em experiências deles requer-se:

[...] um gesto de interrupção, um gesto que é quase impossível nos tempos que correm: requer parar para pensar, parar para olhar, parar para escutar, pensar mais devagar, olhar mais devagar, e escutar mais devagar; parar para sentir, sentir mais devagar, demorar-se nos detalhes, suspender a opinião, suspender o juízo, suspender a vontade, suspender o automatismo da ação, cultivar a atenção e a delicadeza, abrir os olhos e os ouvidos, falar sobre o que nos acontece, aprender a lentidão, escutar aos outros, cultivar a arte do encontro, calar muito, ter paciência e dar-se tempo e espaço (BONDÍA, 2002, p. 22).

Apesar de todos os problemas apontados sobre as limitações do sujeito moderno em ter experiências, ao contrário de Benjamin (1986), Bondía (2002) ainda parece ter esperança quanto à existência dela. Podemos perceber em seu debate sobre o conceito, uma ressignificação do mesmo. Isso coloca a experiência enquanto uma possibilidade para resolver esse impasse da modernidade. E, por meio da reconstrução desse conceito, podemos achar uma saída para novamente dar sentido à vida dos sujeitos, sendo a escola um lugar privilegiado para tal acontecimento. 
Nesse sentido, é importante salientar que a compreensão de experiência trazida por Bondía (2002, 2011) pode contribuir para pensar a EF escolar. Posto isso, surge um questionamento: como será que essa categoria tem se manifestado nessa disciplina escolar? Há espaço para experiência na escola ou apenas para a vivência?

\section{A categoria experiência e a Educação Física}

O debate filosófico sobre experiência pode apresentar alguns elementos importantes para tentar solucionar problemas da sociedade moderna. Mas, se como aponta Benjamin (1986), a pobreza de experiência é um mal que se alastrou por toda a humanidade, poderíamos afirmar que a EF, enquanto disciplina escolar, também tem sofrido com esse empobrecimento? Por esse motivo, nas próximas páginas, apresentaremos um diálogo do conceito da experiência na EF.

Alguns estudos têm sido desenvolvidos no campo da EF. Parte deles tem o intuito de evidenciar a empobrecimento das experiências relacionadas às práticas corporais no âmbito da infância (LÚCIO, et al., 2018; CASTRO; KUNZ, 2015). Outros, porém, reconhecem a necessidade e a importância de tecer diálogos com a categoria da experiência no que tange à formação docente (MEZZAROBA; PICH, 2018).

Diehl, Wittizorecki e Molina Neto (2017) analisaram a produção científica da EF a respeito da experiência e verificaram que esse termo quase sempre aparece de maneira esvaziada dentro dos textos, uma vez que não o explicam conceitualmente. Viu-se, naqueles trabalhos que dialogam profundamente com o conceito de experiência, a relação entre esta e a categoria do trabalho/formação docente. A partir deste mapeamento, os autores concluíram que as publicações utilizam as ideias de experiências advindas tanto do campo da filosofia (Walter Benjamin) como do campo da sociologia (François Dubet). As conclusões de Diehl, Wittizorecki e Molina Neto (2017) vão ao encontro daquelas realizadas também por Figueiredo (2004) ao reconhecerem a experiência como fundamental para a formação docente, influenciando inclusive nas escolhas profissionais, podendo, portanto, serem enriquecidas e/ou empobrecidas na construção das identidades docentes.

Lançando mão do referencial benjaminiano de experiência, Mezzaroba e Pich (2018, p. 698) analisaram as Diretrizes Curriculares Nacionais para a formação de professores de Educação Básica e também as Diretrizes Curriculares Nacionais para a formação de professores de EF e constataram que os documentos oficiais não dão margem para os saberes pautados pela experiência, sobretudo pelo fato de 
esses documentos privilegiarem dimensões técnicas e práticas que precisam ser conduzidas pelo professor. Nesse sentido,

Uma educação que permite experiência, então, não pode ser algo tão cronometrado como a que temos, com a ideia de um caminho reto, seguro, definitivo. Pautar uma crítica a esse tempo que vivemos se mostra como o começo para se possuir experiência na modernidade, compreendendo seus códigos, suas normas, seus valores sociais/morais etc. (MEZZAROBA; PICH, 2018, p. 698).

Mas afinal, qual a relação que a pobreza de experiências pode ter com a EF? Ora, os sujeitos que se acostumaram com pouco, que foram envolvidos por essa pobreza, tornar-se-ão pessoas que não anseiam por experiências, portanto não valorizam o aprendizado de novos conhecimentos e, certamente, não valorizarão o aprendizado de novas práticas corporais. Com isso, os alunos tornam-se sujeitos que não se sentem motivados para as experiências que podem ter com seu corpo, muito menos, anseiam por novos aprendizados, limitando-se, quando muito, há uma mera vivência corporal.

Como bem ressaltado por Fensterseifer (2009), as experiências humanas são traduzidas por meio das linguagens. Essas linguagens também se referem às atividades ligadas às práticas corporais. Nesse sentido, Almeida e Fensterseifer (2011) procuram compreender qual o lugar da experiência no âmbito da EF e alertam, de maneira crítica, para as incursões epistemológicas modernas que tentaram transformar a experiência em experimento, retirando, assim, sua historicidade. De tal modo, Almeida e Fensterseifer (2011) afirmam que a experiência está desaparecendo.

Silva et al. (2009), dialogando com Benjamin, ressaltam que a pobreza de experiência tem expropriado do sujeito toda sua subjetividade, traduzida em uma "objetivação do corpo" que o descaracteriza de suas qualidades humanas e o transforma num objeto. Assim, "a experiência, nesse sentido, não é subjetiva, vivida pelo eu, mas um conjunto de atribuições em terceira pessoa - ele, o corpo, o qual deve ser controlado e do qual se deve desconfiar por seus impulsos naturais ao prazer" (SILVA et $a l, 2009$, p. 12). Kunz (2005) diz que as aulas de EF na escola se pautam por uma lógica fragmentada, ora em relação à duração das atividades, ora em relação aos conteúdos trabalhados. Nesse sentido, pensar na experiência dentro deste contexto é algo complexo. Na esteira de Kunz, podemos afirmar que, durante as aulas de EF escolar, os jovens se relacionam mais com as vivências (efêmeras) do que com experiências (processos internalizados na consciência). Acreditamos, de acordo com Kunz (2005), que a experiência só existe diante do "conhecer-se" livre e autônomo. 
Hildebrandt-Stramann (2009) defende, a partir de cinco teses ${ }^{4}$, que o movimento humano deve ser apreendido levando em consideração a experiência. Como bem salientou Castro (2018), HildebrandtStramann acredita que o movimento humano se realiza no diálogo do homem com o mundo, levando em consideração diferentes maneiras de se-movimentar. Nesse sentido, para Castro (2018), o professor de EF pode induzir os estudantes a realizarem experiências corporais sem o intuito de querer para si o controle das atividades desenvolvidas nas aulas. A esse respeito, salienta Kunz (2012, p. 20), a experiência parece consistir na apropriação do que foi ensinado, transformando e dando sentido e significado para a realidade do aluno.

Almeida e Fensterseifer (2011, p. 259) sugerem que, no que tange a EF, passemos a trabalhar mais na lógica da experiência do que do experimento, pois este está mais ligado a uma mera vivência com o conteúdo apreendido. Isso significa a necessidade de abrir espaço para as incertezas e contradições existentes nas relações humanas. Desse modo, os autores propõem uma aula de atletismo tendo a experiência como protagonista:

A turma foi dividida em grupos e cada grupo deveria estruturar um espaço de corrida e de salto com os materiais disponíveis no bosque e experimentá-lo. Após a experimentação nos grupos, estruturamos uma única pista com cada "estação" criada pelos grupos e novamente houve uma experimentação, agora de forma coletiva. Percebemos nesta aula como os alunos tentaram resolver em seus grupos a construção da pista de obstáculos; como cada aluno, a seu modo, resolvia o problema de superar o obstáculo: por exemplo, alguns imprimiam maior velocidade, outros tomavam uma distância maior, adotando um estilo próprio de saltar sem a utilização de uma técnica pré-definida [...] podemos afirmar que o sujeito histórico da experiência foi considerado (ALMEIDA; FENSTERSEIFER, 2011, p. 259).

Portanto, para Almeida e Fensterseifer (2011), conhecer as práticas corporais significa realizar as experiências menos no sentido de controlá-las e mais no intuito de se entregar as situações inesperadas. É nesse sentido que é possível vislumbrar uma possibilidade de ensino, pois nelas o professor de EF enriquecerá suas aulas estimulando seus alunos para que busquem e apreciem as experiências educativas.

Abordando outra situação corriqueira do universo escolar, imaginemos uma aula de futsal na qual o aluno fique a olhar para o professor durante todo o acontecimento da aula, ora executando o movimento técnico que lhe é determinado, ora voltando para seu lugar e aguardando sua vez para reproduzir o movimento. Se esse aluno for questionado sobre como ele se sentiu e/ou o que percebeu em durante a aula, (se algo o tocou, sensibilizou, provocou mudanças no seu eu) e ele não souber responder ou apenas

\footnotetext{
${ }^{4}$ Hildebrandt-Stramann (2009) acredita que a experiência diante do movimento deve levar em consideração: 1) a autenticidade da experiência; 2) a experiência como diálogo; 3) experiência como ação efetiva; 4) a experiência como a incorporação do desconhecido e do novo; 5) a experiência é um auto esboço projetivo.
} 
disser que aprendeu a fazer o que lhe foi pedido, não se pode afirmar que sua experiência foi enriquecida ou que sequer ele passou por uma experiência. Ao contrário disso, ele apenas foi um executor de movimentos sem sentido, e continuou pobre de experiências, já que, nesse exemplo, tanto o docente como o discente estavam influenciados por atividades de fácil manipulação e controle típicos do experimento e não da experiência.

Nesse sentido, Fabri, Rossi e Ferreira (2016) buscaram compreender as narrativas dos estudantes de ensino médio a respeito de suas experiências nas aulas de EF escolar. As narrativas dos estudantes foram separadas entre aquelas de experiências negativas e as relacionadas às experiências positivas. Para as autoras, um momento possível de se ter experiências nas aulas de EF ocorre durante um jogo, no qual não importa saber do que trata o jogo, ou que se pensa sobre o jogo, mas sim, quais as possibilidades de se formar pelo movimento, ser tocado por ele (jogo), sensibilizado. Isso acontece na relação estabelecida com aquela prática, a qual possibilitará um enriquecimento da experiência. As autoras concluíram seu estudo demonstrando que valorizar as experiências vividas pelos estudantes é fundamental, sobretudo porque potencializa as reflexões no que tange as ações pedagógicas dos docentes e também reconhece a experiência discente como um saber.

Castro e Kunz (2015) também consideram que é fundamental valorizar e compreender as experiências dos alunos. Para eles, no âmbito da educação infantil, é importante que os pais e os professores acabem com o controle e o disciplinamento constante do comportamento das crianças. Para tal, Castro e Kunz (2015) defendem que as brincadeiras sejam atividades autônomas e livres, oferecendo experiências corporais sensíveis para as crianças e não meras reproduções que mais se parecem com experimentos.

Por meio do que foi exposto, seguindo a orientação de Bondía (2002), há muitas possibilidades de enriquecimento do movimento nas aulas de EF através do ensino das práticas corporais. O fator determinante está no fato de que as aulas devem ser desenvolvidas segundo o par experiência/sentido. Outro ponto importante de se ressaltar diz respeito ao fato de as experiências serem um ponto de ligação entre o passado e o futuro. Assim, ela é um dos mecanismos que possibilita o acesso e transmissão de todo o patrimônio histórico de um determinado povo às novas gerações. Com o empobrecimento da EF o que resta são as vivências corporais, que apenas proporcionam um experimento genérico por parte do aluno, tornando-o um reprodutor de gestos. 


\section{Conclusão}

É evidente que a EF, apesar de toda contradição que permeia a área, ainda se configura como um campo do conhecimento que possibilita debates e reflexões. Nesse sentido, pensar novas possibilidades de ensino que possam responder às necessidades que a contemporaneidade necessita torna-se questão emergencial. A partir disso, acreditamos que a categoria da experiência tem muito a contribuir.

Sendo assim, procuramos, com este ensaio, estabelecer diálogo entre a categoria da experiência e o campo da EF na tentativa de contribuir para este debate, ainda introdutório. Nesse sentido, defendemos a formação de uma tríade para se pensar a EF escolar. Tríade esta que é composta pelas práticas corporais/experiência/Educação Física. Desse modo, não necessitaremos engessar as práticas corporais com o uso excessivo de regras e fundamentos técnicos pré-moldados, bem como não precisaremos dar tratos pedagógicos demasiadamente fechados para essas práticas, uma vez que reconhecer nossa insuficiência em controlá-las é ter consciência de que os propósitos da educação escolar também podem ser respondidos por esta tríade.

Talvez esse seja o ponto que mais afaste o aprendizado de algo novo, numa ação positiva, num fazer carregado de sentido para o aprendiz. É a partir do inesperado e da incerteza que o a aluno pode explorar sua subjetividade. Esse diagnóstico é importante para um ensino que almeja o aprendizado tendo como elemento constitutivo a experiência livre e autônoma.

Nesse sentido, para que haja aprendizado de alguma prática corporal no ambiente escolar, o sujeito tem que ser sensibilizado, tocado de alguma maneira, fazendo com o que aquilo que se aprendeu seja incorporado à sua existência, que faça sentido para sua vida. Para tal, é preciso que algo aconteça a esse sujeito durante o aprendizado para que o se-movimentar se materialize como uma experiência.

Todas as reflexões, introdutoriamente, contidas neste ensaio podem ser respondidas e/ou problematizadas se nos debruçarmos mais sobre a categoria experiência e sua relação com a EF escolar. Trata-se de um investimento válido e quem sabe, algum dia, poderemos afirmar: há muita experiência nas experiências!

\section{Referências}

AGAMBEN, Giorgio. Infância e História: destruição da experiência e origem da história. Editora UFMG, Belo Horizonte, 2005. 
ALMEIDA, Luciano de; FENSTERSEIFER, Paulo Evaldo. O lugar da experiência no âmbito da Educação Física. Movimento, Porto Alegre, v. 17, n. 4, out./dez. p. 247-263. 2011.

BENJAMIN, Walter. Magia, Técnica, Arte e Política. Traduzido por Paulo Sérgio Roaunet. São Paulo: Brasiliense, 1986.

Reflexões: a criança, o brinquedo, a educação. São Paulo, Summus, 1984.

BONDÍA, Jorge Larrosa. Notas sobre a experiência e o saber de experiência. São Paulo: Revista Brasileira de Educação, n. 19, 2002, p. 20-169.

Experiência e alteridade em educação. Revista Reflexão e Ação. Santa Cruz do Sul, v. 19, n. 2, p. 4-27, dez. 2011.

CALOU, Ângela Lima; MARCIEL, Marta Maria Aragão. Modernidade e experiência em "sobre alguns temas em Baudelaire” de Walter Benjamin. Perspectiva Filosófica, vol. 44, n. 1, 2017.

CAStellani filHO, Lino. Política Educacional e Educação Física. Campinas: Autores Associados, 1999.

CASTRO, Felipe Barroso de. Educação Física aberta à experiência: um diálogo com as cinco teses de Hildebrandt-Stramann (2009). Kinesis, v. 36, p. 115-127, 2018.

CASTRO, Felipe Barroso de; KUNZ, Elenor. O controle da subjetividade e das experiências corporais sensíveis: implicações para o brincar e se-movimentar da criança. Motrivivência, Florianópolis, v. 27 , n. 45, p. 44-57, set. 2015.

DIEHL, Vera Regina Oliveira; WITTIZORECKI, Elisandro Schultz; NETO, Vicente Molina. Estado do Conhecimento: a categoria experiência no âmbito da Educação Física. Goiânia: Pensar a Prática, v. 20, n. 1, mar. 2017.

FABRI, Eliane; ROSSI, Fernanda; FERREIRA Lilian. Episódios marcantes das aulas de educação física: valorizando as experiências dos alunos por meio de narrativas. Movimento, v. 22, n. 2, p. 583-596, 2016.

FENSTERSEIFER, Paulo Evaldo. Linguagem, hermenêutica e atividade epistemológica na Educação Física. Movimento, Porto Alegre, v. 15, n. 04, p. 243-256, 2009.

FIGUEIREDO, Zenólia Cristina. Formação docente em educação física: experiências sociais e relação com o saber. Movimento, Porto Alegre, v. 10, n. 1, p. 89-111. jan./abr. 2004.

GAGNEBIN, Jeanne Marie. Lembrar, escrever, esquecer. São Paulo: 34, 2006.

GIL, Antonio Carlos. Como elaborar projetos de pesquisa. São Paulo, 2008.

GONZÁLEZ, Fernando J.; FENSTERSEIFER, Paulo Evaldo. Entre o "não mais" e o "ainda não": pensando saídas do não lugar da educação física escolar II. Cadernos de Formação RBCE. p. 10-21, mar. 2010. 
HILDEBRANDT-STRAMANN, Reiner. Educação física aberta à experiência: uma concepção didática em discussão. Rio de Janeiro: Imperial Novo Milênio, 2009.

KUNZ, Elenor. Práticas Didáticas para um "Conhecimento de Si” de crianças e jovens na Educação Física. In: . Didática da Educação Física. 4 ed. Unijuí, 2012.

. Se-movimentar. In: GONZÁLEZ, F. J.; FENSTERSEIFER, P. E. (Orgs.). Dicionário crítico de educação física. Ijuí: Editora Unijuí, 2005.

LAZZAROTTI FILHO, Ari. et al. O termo "práticas corporais" na literatura científica brasileira e sua repercussão no campo da educação física. Movimento, v. 16, n. 1, jun., 2009.

LÚCIO, Géssica Adriana de Carvalho et al. Experiências de ensino e subjetividades imanentes configurando práticas de professores de Educação Física da educação infantil. Motrivivência, Florianópolis, v. 30, n. 56, p. 100-119, nov. 2018.

LUCKESI, Cipriano Carlos. Desenvolvimento dos estados de consciência e ludicidade. In: Interfaces da Educação, Cadernos de Pesquisa - Núcleo de Filosofia e História da Educação, Programa de PósGraduação em Educação, UFBA, vol. 2, n. 1, 1998.

MEZZAROBA, Cristiano; PICH, Santiago. O conceito de experiência em Benjamin: considerações analisando as diretrizes curriculares nacionais para a formação de professores de educação básica e de professores de Educação Física. Pensar a Prática, v. 21, n. 3, 28 set. 2018.

SILVA, Ana Márcia et al. Corpo e experiência: para pensar as práticas corporais. In: FALCÃO, J. L.; SARAIVA. M. C. (Orgs). Práticas corporais no contexto contemporâneo: (in)tensas experiências. Florianópolis, SC: Copiart, 2009.

SILVA, João Gabriel. O castelo da experiencia: Walter Benjamin e a literatura medieval. Dissertação (Mestrado em Psicologia) - Universidade Federal Fluminense, Instituto de Ciências Humanas e Filosofia, Departamento de Psicologia, 2012.

TRIVIÑOS, Augusto Nibaldo Silva. Introdução à pesquisa em ciências sociais: a pesquisa qualitativa em educação. São Paulo: Atlas, 1987.

WELLER, Wivian; PFAFF, N. Pesquisa qualitativa em Educação: origens e desenvolvimentos. In: WELLER, W. A.; PFAFF, N (Org.). Metodologias da pesquisa qualitativa em educação: teoria e prática. Petrópolis: Vozes, 2011.

\section{Como citar este artigo}

HOLANDA, G. I. S.; BUNGENSTAB, G. C. A Educação Física escolar e seus dilemas contemporâneos: há pouca experiência nas experiências? Revista Kinesis, Santa Maria, v.39, p. 01-14, 2021.

*O presente trabalho não contou com apoio financeiro de nenhuma natureza para sua realização. 